Jurnal Keperawatan Silampari

Volume 5, Nomor 1, Desember 2021

e-ISSN: 2581-1975

p-ISSN: 2597-7482

DOI: https://doi.org/10.31539/jks.v5i1.2587

\title{
KARAKTERISTIK DAN BUDAYA KESELAMATAN PASIEN TERHADAP INSIDEN KESELAMATAN PASIEN
}

\author{
Arni Wianti ${ }^{1}$, Asep Setiawan ${ }^{2}$, Murtiningsih $^{3}$, Budiman $^{4}$, Lilis Rohayani $^{5}$ \\ Sekolah Tinggi Ilmu Kesehatan Jenderal Achmad Yani Cimahi ${ }^{1,2,3,4,5}$ \\ arnie5sg@gmail.com ${ }^{1}$
}

\begin{abstract}
ABSTRAK
Penelitian ini bertujuan untuk mengetahui faktor yang mempengaruhi budaya keselamatan pasien terhadap insiden keselamatan pasien di rumah sakit umum Kota dan Kabupaten Cirebon yang dilihat dari karakteristik perawat dan budaya keselamatan pasien. Jenis penelitian yang digunakan adalah kuantitatif non eksperimental dengan menggunakan desain penelitian cross sectional. Hasil penelitian menunjukkan bahwa karakteristik perawat yang mempengaruhi insiden keselamatan pasien adalah pendidikan dengan OR 5,613dan jenis kelamin sebesar dengan OR 4,478. Simpulan, pendidikan, jenis kelamin, dukungan manajemen, kerjasama antar unit serta handsoff dan transisi merupakan faktor yang berpengaruh terhadap insiden keselamatan pasien.
\end{abstract}

Kata Kunci : Budaya Keselamatan Pasien, Insiden Keselamatan Pasien, Karakteristik Perawat

\section{ABSTRACT}

This study aims to determine the factors that influence patient safety culture on patient safety incidents in Cirebon City and Regency public hospitals which are seen from the characteristics of nurses and patient safety culture. The type of research used is nonexperimental quantitative using a cross-sectional research design. The results showed that the characteristics of nurses that influenced patient safety incidents were education with an OR of 5,613 and gender with an OR of 4,478. In conclusion, education, gender, management support, cooperation between units as well as handsoff and transition are factors that influence patient safety incidents.

Keywords: Patient Safety Culture, Patient Safety Incident, Nurse Characteristics

\section{PENDAHULUAN}

Keselamatan pasien dijadikan prioritas yang utama dalam pelayanan kesehatan dan pelayanan keperawatan sekaligus sebagai aspek paling penting dari manajemen yang berkualitas. Keselamatan pasien menurut World Health Organization (WHO) adalah tidak ada bahaya yang mengancam kepada pasien selama proses pelayanan kesehatan. Rumah sakit sebagai institusi pemberi pelayanan kesehatan harus dapat menjamin pelayanan kesehatan yang diberikan kepada pasien (Hadi, 2017).

Kementerian Kesehatan Republik Indonesia telah mengeluarkan Peraturan Menteri Kesehatan No. 11 Tahun 2017 tentang keselamatan pasien di rumah sakit yang menjadi tonggak utama operasionalisasi keselamatan pasien di rumah sakit seluruh Indonesia. Banyak rumah sakit di Indonesia yang telah berupaya membangun dan 
mengembangkan keselamatan pasien, namun upaya tersebut dilaksanakan berdasarkan pemahaman manajemen terhadap keselamatan pasien. Peraturan mentri ini memberikan panduan bagi manajemen rumah sakit agar dapat menjalankan spirit keselamatan pasien secara utuh (Kementerian Kesehatan, 2017).

Sasaran keselamatan pasien merupakan syarat untuk diterapkan di semua rumah sakit yang diakreditasi oleh Standar Nasional Akreditasi Rumah Sakit (SNARS). Adapun maksud dan tujuan Sasaran Keselamatan Pasien adalah untuk mendorong rumah sakit agar melakukan perbaikan spesifik dalam keselamatan pasien. Sasaran ini menyoroti bagian-bagian yang bermasalah dalam pelayanan rumah sakit dan menjelaskan bukti serta solusi dari konsensus para ahli atas permasalahan ini. Sistem yang baik akan berdampak pada peningkatan mutu pelayanan rumah sakit dan keselamatan pasien (SNARS, 2018).

Komite Keselamatan Pasien Rumah Sakit (KKPRS), menyatakan kejadian keselamatan pasien merupakan media belajar dari proses kesalahan dalam pelayanan di rumah sakit. Insiden keselamatan pasien adalah kejadian atau situasi yang dapat menyebabkan atau berpotensi mengakibatkan cidera yang seharusnya tidak terjadi. Insiden Keselamatan Pasien di rumah sakit memiliki jenis-jenis yang berbeda terdiri dari: Kejadian Potensial Cedera (KPC), Kejadian Nyaris Cidera (KNC), Kejadian Tidak Cedera (KTC), Kejadian Tidak Diharapkan (KTD) atau adverse event dan kejadian sentinel atau sentinel event (Kementerian Kesehatan, 2017).

Dari tahun 2006 - 2011, KPPRS melaporkan terdapat 877 laporan insiden keselamatan pasien. Sementara untuk kurun waktu 2015 - 2019 laporan insiden keselamatan pasien terdapat 11.558 kasus, dan peningkatan jenis insiden dari kurun waktu tersebut sekitar $7-12 \%$. Begitupun dengan jumlah Rumah Sakit yang melaporkan insiden keselamatan pasien naik 7\% pada tahun 2019 yang sebesar 12\% dibandingkan dengan tahun 2018 sebesar 5\%. Angka kematian pasien akibat insiden keselamatan pasien pada tahun 2019 sebesar 171 kasus, hal ini akan mengakibatkan kurangnya kepercayaan dalam pelayanan kesehatan, sehingga kecenderungan yang terjadi adalah rumah sakit hanya melaporkan kejadian yang cedera ringan atau tidak ada cedera (Daud, 2020).

Dari hasil wawancara dan observasi laporan insiden keselamatan pasien tahun 2019, pada tanggal tanggal 3 Maret dan 28 Juli 2020 kepada tim Peningkatan Mutu dan Keselamatan Pasien (PMKP) di dua Rumah Sakit di Wilayah Cirebon, didapatkan hasil laporan insiden keselamatan pasien, data Insiden keselamatan pasien yang terdiri dari kejadian potensial cidera sebanyak 145 kasus, kejadian nyaris cidera sebanyak 46 kasus, kejadian tidak diharapkan sebanyak 62 kasus dan kejadian tidak cidera sebanyak 27 kasus.

Ada beberapa faktor yang mempengaruhi rendahnya pelaporan insiden keselamatan pasien yaitu : (1) takut disalahkan, (2) komitmen kurang dari manajemen dan unit terkait, (3) tidak ada reward dari rumah sakit jika melaporkan, (4) tidak tahu batasan mana atau apa yang harus dilaporkan, (5) sosialisasi insiden keselamatan pasien belum menyeluruh ke semua staf, (6) belum ikut pelatihan tentang keselamatan pasien untuk semua staf rumah sakit, selain itu juga hal yang menyebabkan rendahnya pelaporan Insiden, yaitu : (1) kurangnya pemahaman petugas untuk melaporkan insiden keselamatan pasien, (2) kurang optimalnya pelaksanaan sistem pelaporan Insiden keselamatan pasien, (3) ketakutan untuk melapor dan tingginya beban kerja tenaga kesehatan (Hwang et al., 2019). 
Sehingga peneliti melakukan penelitian untuk mengetahui faktor karakteristik dan budaya keselamatan pasien terhadap insiden keselamatan pasien terutama dalam masa pandemi COVID 19 dimana perawat dihadapkan pada keadaan yang memerlukan perlindungan lebih dibandingkan dengan sebelumnya dengan harus mengedepankan pelayanan yang berkualitas kepada pasien dan keluarga tanpa harus terkena resiko COVID 19.

\section{METODE PENELITIAN}

Penelitian ini menggunakan pendekatan cross sectional untuk mengetahui korelasi antara faktor-faktor risiko yaitu usia, jenis kelamin, pendidikan, masa kerja, dan 12 item budaya keselamatan pasien dengan insiden keselamatan pasien yang terdiri dari kejadian tidak diharapkan, kejadian nyaris cedera, kejadian tidak cedera, kejadian potensial cedera, dan sentinel. Sampel dalam penelitian ini sebanyak 85 orang perawat di dua Rumah Sakit dengan pengambilannya secara proportional random sampling.

Pengambilan data secara primer dan sekunder, data primer diperoleh dengan memberikan kuesioner melalui google form yang terdiri dari biodata serta kuesioner hospital survey on patient safety culture dengan total 42 item pertanyaan yang mencakup 12 dimensi budaya keselamatan pasien kepada perawat, dan data sekunder yang diperoleh dari laporan program kerja PMKP tahun 2019.

Analisis data pada penelitian ini menggunakan software SPSS dan yang dipakai dalam analisis datanya adalah analisis regresi logistik dengan korelasi kanonik (canonical analysis).

\section{HASIL PENELITIAN}

Tabel. 1

Pemodelan Faktor-Faktor yang Mempengaruhi Insiden Keselamatan Pasien

\begin{tabular}{clc}
\hline No & \multicolumn{1}{c}{ Faktor yang Mempengaruhi } & OR \\
\hline 1 & Dukungan Manajemen & 6.796 \\
2 & Pendidikan & 5.613 \\
3 & Kerjasama Antar Unit & 4.913 \\
4 & Jenis Kelamin & 4.478 \\
5 & Handsoff dan transisi & 3.479 \\
\hline
\end{tabular}

Berdasarkan tabel 1 menunjukkan bahwa faktor yang berpengaruh terhadap insiden keselamatan pasien adalah dukungan manajemen dengan OR sebesar 6.796.

\section{PEMBAHASAN}

Keselamatan pasien merupakan salah satu nilai untuk menjamin berlangsungnya pelayanan kesehatan yang paripurna di rumah sakit. Keselamatan pasien sebagai pelayanan yang tidak menyakiti pasien maupun sistem perawatan pasien di rumah sakit yang lebih aman. Pengukuran resiko, pengenalan dan pengelolaan kesehatan pasien, pencatatan dan pengkuran kasus, pembelajaran kasus dan tindakan serta solusi implementasi untuk mengurangi resiko, tujuan sistem keselamatan pasien rumah sakit adalah terciptanya budaya keselamatan pasien di rumah sakit, meningkatkan akuntabilitas rumah sakit terhadap pasien dan masyarakat. 
Berdasarkan hasil penelitian, dukungan dari pihak manajemen keperawatan didapatkan OR sebesar 6.796 sehingga dukungan dari pihak manajemen berpengaruh sangat besar terhadap suatu kejadian insiden keselamatan pasien. Perawat dalam hal ini mendapatkan perhatian yang berlebih dikarenakan pekerjaan yang paling banyak berinteraksi dengan pasien, sehingga apabila ada kesalahan perawat terlebih dahulu yang akan dicermati.

Dukungan manajemen terhadap pelaksanaan keselamatan pasien adalah pihak manajemen menyediakan sumber daya, kebijakan, dan menciptakan suasana yang mendukung dalam pelaksanaan keselamatan pasien demi mencegah insiden keselamatan pasien. Salah satu dari tujuh langkah menuju keselamatan pasien rumah sakit adalah memberi dukungan kepada staf. Pelaksanaan manajemen keselamatan memerlukan dukungan dari organisasi dan petugas pelayanan. Kepemimpinan, budaya keselamatan, pemenuhan struktur dan sistem yang baik dan pengelolaan manajemen merupakan dukungan untuk pemenuhan keselamatan pasien rumah sakit. Melalui program keselamatan pasien dengan prioritas pada penguatan kepemimpinan dan fungsi manajemen, penerapan budaya keselamatan di pelayanan serta peningkatan pengetahuan tentang keselamatan pasien akan mampu meningkatkan kualitas dan keselamatan pasien di rumah sakit.

Pada penelitian ini variabel tingkat pendidikan didapatkan hasil OR sebesar 5.613, dengan demikian bahwa tingkat pendidikan akan berpengaruh 5.613 kali terhadap penerapan patient safety. Tingkat pendidikan merupakan salah satu faktor penting yang patut dipertimbangkan dalam mengalokasikan sumber daya manusia. Didapatkan hasil perawat dengan pendidikan D3 dan S1 sebesar 54.1\% lebih besar dibandingkan dengan pendidikan Ners dan S2 Keperawatan. Di awal karirnya pada kedua rumah sakit tersebut sebagian besar perawat berpendidikan D3 keperawatan, setelah itu melanjutkan pendidikan untuk mendapatkan gelar Ners, pada saat peneliti melakukan penelitian ini banyak diantara perawat yang baru saja menyelesaikan program S1 dan ada yang masih dalam pendidikan untuk memperoleh gelar Nersnya.

Hal ini telah sesuai dengan peraturan Undang-Undang Nomor 38 Tahun 2014 tentang Keperawatan dan Peraturan Menteri Kesehatan Nomor 26 tahun 2019 tentang Peraturan Pelaksanaan UU 38 tahun 2018 mengenai standar pelayanan minimal rumah sakit bahwa tenaga perawat yang dianggap berkompeten dalam memberikan pelayanan adalah perawat dengan jenjang pendidikan minimal D3, sehingga diharapkan bahwa tingkat pendidikan yang lebih baik akan menciptakan budaya kerja yang lebih baik. Oleh karena itu ini dijadikan dasar bagi pihak manajemen rumah sakit dalam memberdayakan perawat dalam memberikakan pelayanan bagi pasien.

Hasil penelitian ini ditemukan bahwa perawat dengan latar belakang pendidikan S1 dan Ners lebih patuh dalam menerapkan pedoman patient safety dibandingkan dengan perawat yang berpendidikan D3. Tingkat pendidikan yang tinggi dapat mempengaruhi keterampilan perawat dalam menerapkan pedoman patient safety. Tingkat pendidikan merupakan pengalaman yang berfungsi mengembangkan kemampuan dan kualitas kepribadian seseorang, dimana semakin tinggi tingkat pendidikan semakin besar untuk memanfaatkan pengetahuan dan keterampilan. Tingkat pendidikan yang lebih tinggi biasanya menyebabkan seseorang lebih mampu dan bersedia menerima posisi dan tanggungjawabnya (Anwar, 2018).

Berdasarkan hasil penelitian bahwa variabel kerjasama antar unit mempunyai OR 4.913, dengan demikian bahwa kerjasama antar unit akan berpengaruh 4.913 kali terhadap penerapan patient safety. Pada dimensi ini terdapat empat item yaitu 
koordinasi unit dirumah sakit, kerjasama unit dalam melakukan pekerjaan bersamasama, dan kenyamanan staf bekerja dalam memberikan perawatan yang terbaik kepada pasien. Kerjasama antar unit menunjukkan sejauh mana kekompakan petugas antar unit untuk saling berkoordinasi dan bekerjasama dengan baik dalam memberikan pelayanan di rumah sakit. Oleh karena itu diperlukan komunikasi yang efektif diantara anggota tim untuk memainkan peran penting dalam mempromosikan keselamatan pasien. Kegagalan komunikasi harus ditekan oleh semua unit agar tidak membahayakan bagi pasien.

Berdasarkan hasil penelitian bahwa variabel jenis kelamin akan mempengaruhi patient safety sebesar 4.478. Jenis kelamin adalah salah satu faktor yang tidak mengalami perubahan, karena jenis kelamin adalah faktor pasti serta tidak dapat berubah. Dalam penelitian ini, didapatkan bahwa jumlah perawat perempuan masih mendominasi dibandingkan dengan perawat laki-laki sebesar 57,6\%, sehingga pada penelitian ini didapatkan hasil bahwa perawat perempuan mempunyai pengaruh dalam penerapan budaya keselamatan pasien lebih besar dibandingkan dengan perawat lakilaki. Secara psikologis perawat perempuan lebih bersedia dan mampu untuk mematuhi wewenang dan tanggung jawab yang diberikan, sementara pria lebih agresif dan lebih besar kemungkinannya daripada wanita dalam memiliki harapan untuk sukses. Perawat perempuan akan lebih memberikan perhatian kepada pasien dalam melakukan tindakan pelayanan asuhan keperawatan, terutama dalam ruang rawat inap biasa.

Penelitian ini sejalan Etherington et al., (2020) yang menyatakan bahwa ada pengaruh jenis kelamin perempuan dengan OR sebesar 0,91 dalam melakukan praktek pelayanan kesehatan terutama perawatan bedah. Ketika dalam melakukan pelayanan keperawatan, walaupun presentasi perawat perempuan lebih banyak dibandingkan dengan laki-laki akan tetapi dengan adanya kerjasama yang baik diharapkan mampu meningkatkan pelayanan asuhan keperawatan sehingga insiden keselamatan pasien tidak akan terjadi. Selain itu juga, apabila insiden sudah terjadi maka harus cepat diatasi agar tidak menimbulkan cedera yang serius dan pasien merasa puas ketika dirawat di rumah sakit.

Kerjasama antar unit dapat mempengaruhi terjadinya insiden, salah satu contoh dapat terlihat ketika perawat dan tim laboratorium mengambil darah pemeriksaan rutin dengan jelas, adanya jalinan kerjasama yang baik antar unit seperti kenyamanan bekerjasama dengan petugas di unit lain maka tidak akan terjadi insiden, begitu juga sebaliknya. Diperlukannya kerjasama antar unit di rumah sakit karena di rumah sakit terdapat berbagai tim/unit seperti unit kamar operasi, unit ICU, unit farmasi, unit gizi, dan sebagainya.

Berdasarkan hasil penelitian bahwa variabel handsoff dan transisi akan mempengaruhi budaya keselamatan pasien sebesar 3.479, dengan demikian bahwa handsoff dan transisi akan berpengaruh 3.479 kali terhadap penerapan patient safety. Hasil ini juga sejalan dengan penelitian yang dilakukan oleh Alfiani et al., (2018) menyatakan bahwa keselamatan kerja dipengaruhi oleh handsoff dengan peluang sebesar 2,65.

Pemindahan dan pergantian (handoffs dan transition) sangat berkaitan dengan sistem kerjasama dan koordinasi antar petugas kesehatan pada saat pergantian shift kerja. Dalam proses pergantian shift sangat berpotensi terjadinya 81 kehilangan data dan informasi tentang pasien. Kegiatan ini akan sangat mengancam keselamatan pasien jika tidak dilakukan secara baik dan professional, karena informasi pasien yang didapatkan harus diterima secara maksimal. Mandriani et al., (2019) menyatakan bahwa tingkat keberhasilan proses handoffs dan transisi bergantung pada persepsi di antara penyedia 
layanan kesehatan tentang pentingnya prosedur handoffs dan transisi. Dengan demikian, pendidikan staf dan pelatihan adalah suatu keharusan untuk memastikan implementasi handoffs dan transisi yang lebih baik, sehingga diperlukan suatu kerjasama yang baik dari semua pelayanan yang terkait.

Kerjasama antar unit, handoffs dan transisi tidak bisa terpisahkan satu dengan yang lainnya, oleh karena itu Rumah Sakit dalam penerapan patient safety dapat menggunakan komunikasi SBAR (Situation, Background, Assessment, Recommendation). Metode komunikasi ini digunakan pada saat perawat melakukan handover ke pasien dimana hal ini adalah metode terstruktur untuk mengkomunikasikan informasi penting yang membutuhkan perhatian segera dan tindakan berkontribusi terhadap eskalasi yang efektif dan meningkatkan keselamatan pasien. SBAR juga dapat digunakan secara efektif untuk meningkatkan serah terima antara shift atau antara staf di daerah klinis yang sama atau berbeda (SNARS, 2018).

Hal di atas hanya salah satu dalam penerapan patient safety, hal ini tidak dapat berdiri sendiri melainkan dimensi yang satu dengan yang lain saling mempengaruhi). Penerapan budaya keselamatan pasien dikatakan berhasil apabila semua elemen yang ada di dalam rumah sakit menerapkan budaya keselamatan pasien dalam pekerjaannya sehari-hari.

Dalam konsep Patient Centered Care (PCC) sebagai sebuah dimensi dalam menentukan suatu kualitas pelayanan kesehatan. Sebagai seorang perawat wajib dalam menghormati nilai-nilai, pilihan ataupun kebutuhan yang diutarakan pasien. Pelayanan patient centered care ini berpusat dan bermitra dengan pasien dimana adanya keterlibatan pasien, keluarga, perawat serta tenaga kesehatan lainnya yang diperlukan dalam proses pelayanan kesehatan pasien tersebut. Hal yang penting lainnya adalah pasien dan keluarga di-support untuk ikut serta dalam proses keperawatan dan pembuatan keputusan.

Keselamatan pasien di rumah sakit melibatkan partisipasi dari semua petugas kesehatan, terutama perawat. Tidak hanya dilaksanakan oleh perawat pelaksana saja, namun juga dukungan dari semua pihak yang terlibat baik secara langsung atau secara tidak langsung terhadap pasien tersebut. Keselamatan pasien adalah prioritas utama dan harus segera dilaksanakan di rumah sakit karena dapat menyebabkan cedera langsung kepada pasien, terkait dengan kualitas dan nilai rumah sakit serta standar pelayanan yang harus dipenuhi oleh Standar Akreditasi Rumah Sakit terkait untuk versi 2012 yang mengacu pada Joint Commission International (JCI).

Budaya keselamatan yang ditandai dengan adanya alur informasi yang baik dan adanya proses komunikasi yang berkaitan dengan pembelajaran pada saat KTD, memiliki pemimpin yang komit dan eksekutif yang bertanggung jawab serta pendekatan untuk tidak menyalahkan dan tidak memberikan hukuman pada insiden yang dilaporkan merupakan budaya penting yang harus dibangun pada sebuah rumah sakit (Yarnita \& Maswarni, 2019).

\section{SIMPULAN}

Pendidikan, jenis kelamin, dukungan manajemen, kerjasama antar unit serta handsoff dan transisi merupakan faktor yang berpengaruh terhadap insiden keselamatan pasien. 


\section{SARAN}

Semua pihak dalam pelayanan kesehatan harus meningkatkan meningkatkan mutu, motivasi perawat dalam patient safety, sehingga nantinya diharapkan mampu memberikan kenyamanan dan pelayanan yang berkualitas kepada pasien.

\section{DAFTAR PUSTAKA}

Alfiani, F., Artiawati, I. R \& Wulandari, R. Y. (2018). Faktor-Faktor yang Mempengaruhi Pelaporan Insiden Keselamatan Pasien di Rumah Sakit Putera Bahagia Cirebon Tahun 2018. Jurnal Ilmu Kesehatan, 8(1), 11-21. https://ejournal.umc.ac.id/index.php/JIK/article/view/282\%0D\%0A

Anwar, Z. (2018). Mentoring Sebagai Suatu Inovasi Dalam Peningkatan Kinerja. Jurnal of Education and Instruction, 1(1), 21-28. https://journal.ipm2kpe.or.id/index.php/JOEAI/article/view/209

Daud, A. (2020). Komite Nasional Keselamatan Pasien: Sistem Pelaporan dan Pembelajaran Keselamatan Pasien Nasional (SP2KPN). Jakarta: Kementerian Kesehatan RI

Etherington, N., Deng, M., Boet, S., Johnston, A., Mansour, F., Said, H., \& Sun, L. Y. (2020). Impact of Physician's Sex/Gender on Processes of Care, and Clinical Outcomes in Cardiac Operative Care: A Systematic Review. BMJ Open. https://doi.org/10.1136/bmjopen-2020-037139

Hadi, I. (2017). Buku Ajar Manajemen Keselamatan Pasien. Yogyakarta: Deepublish

Hwang, J. I., Kim, S. W., \& Chin, H. J. (2019). Patient Participation in Patient Safety and Its Relationships with Nurses' Patient-Centered Care Competency, Teamwork, and Safety Climate. Asian Nursing Research. https://doi.org/10.1016/j.anr.2019.03.001

Kementerian Kesehatan RI. (2017). Peraturan Menteri Kesehatan Republik Indonesia No 11 Tahun 2017 tentang Keselamatan Pasien. Jakarta: Kementerian Kesehatan RI

Mandriani, E., Hardisman, H., \& Yetti, H. (2019). Analisis Dimensi Budaya Keselamatan Pasien oleh Petugas Kesehatan di RSUD dr Rasidin Padang Tahun 2018. Jurnal Kesehatan Andalas, 8(1), 131. https://doi.org/10.25077/jka.v8i1.981

SNARS. (2018). Standar Nasional Akreditasi Rumah Sakit (1st ed.). http://rspmanguharjo.jatimprov.go.id/wp-content/uploads/2020/09/InstrumenSurvei-SNARS-ed-1-Tahun-2018-1.pdf

Yarnita, Y., \& Maswarni, M. (2019). Budaya Keselamatan Pasien pada Perawat di Instalasi Perawatan Intensive RSUD Arifin Achmad Provinsi Riau. Jurnal Keperawatan Priority,2(2), 109-119. https://media.neliti.com/media/publications/290560-budaya-keselamatan-pasienpada-perawat-d-0aaf6277.pdf 